\title{
Coarctectomy reduces neoaortic arch obstruction in hypoplastic left heart syndrome
}

\author{
Victor Bautista-Hernandez, MD, ${ }^{a}$ Gerald R. Marx, MD, ${ }^{b}$ Kimberlee Gauvreau, ScD, ${ }^{\text {b }}$ Frank A. Pigula, MD, \\ Emile A. Bacha, MD, ${ }^{a}$ John E. Mayer, Jr, MD, and Pedro J. del Nido, MD ${ }^{a}$
}

From the Departments of Cardiac Surgery and Cardiology, ${ }^{\text {b }}$ Children's Hospital Boston, Harvard Medical School, Boston, Mass.

Dr Bautista-Hernandez was supported by University Hospital "Virgen de la Arrixaca" and The Real Colegio Complutense at Harvard University.

Read at the Eighty-sixth Annual Meeting of The American Association for Thoracic Surgery, Philadelphia, Pa, April 29-May 3, 2006.

Received for publication April 26, 2006; revisions received Dec 6, 2006; accepted for publication Dec 13, 2006.

Address for reprints: Pedro J. del Nido, MD, Department of Cardiac Surgery, Children's Hospital Boston, 300 Longwood Ave, Bader 273, Boston, MA 02115 (E-mail: pedro.delnido@tch.harvard.edu).

J Thorac Cardiovasc Surg 2007;133:1540-6 $0022-5223 / \$ 32.00$

Copyright (๑) 2007 by The American Association for Thoracic Surgery

doi:10.1016/j.jtcvs.2006.12.067
Objective: Neoaortic arch obstruction after stage I palliation is an important risk factor affecting interstage mortality in patients with hypoplastic left heart syndrome, with no accepted standard surgical approach. We sought to determine the efficacy of different techniques for aortic arch reconstruction to reduce the incidence of postoperative neoaortic arch obstruction.

Methods: From January 2000 through June 2005, 210 patients underwent stage I palliation. To enlarge the aortic arch, 12 (6\%) patients had a direct connection, 115 (55\%) patients had an aortic homograft, $53(25 \%)$ patients had a pulmonary homograft patch, and $30(14 \%)$ patients had autologous pericardium. Independent of the technique for aortic enlargement, 55 (26\%) children had coarctectomy.

Results: Eighty patients had a significant arch gradient, as determined by means of echocardiography, and of these, 50 required balloon angioplasty, surgical arch augmentation, or both. Preoperative aortic coarctation was consistently linked to neoaortic arch obstruction $(P=.032)$. Patients having aortic arch enlargement by means of direct connection or with autologous pericardium were less likely to have neoaortic arch obstruction $(P=.049)$. Coarctectomy resulted in a lower incidence of neoaortic arch obstruction, as determined by means of echocardiography ( $P=$ $.015)$, or need for reintervention $(P=.01)$.

Conclusions: Patients with hypoplastic left heart syndrome undergoing aortic arch enlargement with autologous tissue are less likely to require intervention for neoaortic arch obstruction compared with those having homograft patch reconstruction. Excision of all ductal tissue by means of coarctectomy reduces the risk of recurrent aortic arch obstruction. An aggressive approach to reconstruction of the arch and the use of autologous tissue at the time of stage I palliation is advocated.

$\mathrm{H}$ ypoplastic left heart syndrome (HLHS) is the most frequently encountered congenital heart malformation characterized by a single well-developed ventricle. Its incidence is about $7 \%$ of all infants presenting with cardiac disease in the first year of life. ${ }^{1}$ HLHS involves a wide spectrum of underdevelopment of the left-sided heart structures, characterized by aortic and/or mitral valve atresia or severe stenosis with hypoplasia or absence of the left ventricle. ${ }^{2,3}$ Coarctation of the aorta is usually associated with the anomaly. ${ }^{4,5}$ The first successful palliative operation for this complex cardiac anomaly was reported by Norwood and colleagues in $1983 .{ }^{6}$ The surgical technique achieved reconstruction of the aortic arch by means of direct anastomosis between the pulmonary artery trunk and the diminutive aorta. Although this procedure has been advocated recently by some groups, ${ }^{7-10}$ it was abandoned by Norwood and others because surgical anatomy was not usually deemed suitable to carry out this approach, with recurrent arch obstruction and left pulmonary artery stenosis being frequently observed. Augmentation of the aorta and arch remains a critical step in the Norwood operation, and surgical 


\section{Abbreviations and Acronyms \\ HLHS $=$ hypoplastic left heart syndrome \\ $\mathrm{NAO}=$ neoaortic arch obstruction}

technical problems have been reported as the leading cause of sudden circulatory arrest and death early after the Norwood operation. ${ }^{11,12}$ Neoaortic arch obstruction (NAO) is one of the key features affecting morbidity and mortality after the stage I palliation or Norwood operation, with a reported incidence ranging from $11 \%$ to $37 \% .^{13-17}$ Recurrent arch obstruction can result in decreased cardiac output, ventricular dysfunction, and tricuspid regurgitation. However, there is not a standard surgical approach for the reconstruction of the aorta at the time of stage I palliation.

The aim of this study was to compare the various surgical techniques used to augment the aortic arch at the time of the stage I procedure with respect to recurrence of NAO and need for balloon dilation, repeat surgical reconstruction, or both.

\section{Materials and Methods Patients}

We retrospectively reviewed all patients undergoing a stage I palliation procedure at Children's Hospital Boston from January 2000 through June 2005. The diagnosis for HLHS was based on echocardiographic evidence of diminutive ascending aorta, aortic atresia or stenosis, mitral atresia or stenosis, and hypoplastic left ventricle. Patients with anatomic variants of HLHS who underwent stage I palliation were also included in our study population. Preoperative evaluation of the aortic arch was performed by using echocardiography. Coarctation was defined as the presence of a patent posterior shelf in the ductal area. Evaluation of the aortic arch was done with echocardiography at the time of the pre-stage II echocardiogram or most recent echocardiography in the patients who had not had the stage II procedure. A persistent mean systolic gradient across the arch equal to or greater than $15 \mathrm{~mm} \mathrm{Hg}$ was considered significant. Need for balloon angioplasty or surgical aortic arch reconstruction was also recorded. The decision for reintervention was made on the basis of echocardiographic gradients plus catheterization or magnetic resonance imaging data. This study was approved by the Children's Hospital Boston Institutional Review Board.

\section{Surgical Procedure}

The surgical procedure for coarctectomy entails resection of the aorta at the level of coarctation, wide resection of all the ductal tissue and the posterior shelf, extended counterincision distally in the anterolateral aspect of the descending thoracic aorta, mobilization of the supra-aortic trunks, and direct end-to-end anastomosis between the greater curvature of the native aortic arch and the descending aorta, along with patch augmentation of the aorta with autologous pericardium treated with glutaraldehyde $4 \%$ for 10 minutes or heterologous tissue.
Regardless of the surgeon's preferences, in the vast majority of patients, our approach for HLHS entails deep hypothermic circulatory arrest, with $\mathrm{pH}$-stat for less than $28^{\circ} \mathrm{C}$ and a hematocrit value of greater than $25 \%$. One hundred forty-four patients in our series underwent delayed sternal closure.

\section{Statistical Analysis}

The 2 primary outcome variables were recurrence of NAO and need for balloon dilation, repeat surgical reconstruction, or both, and a secondary outcome variable was in-hospital mortality. Relationships between patient and surgical characteristics and outcomes were evaluated by using the Fisher exact test. Multivariate analyses were performed with logistic regression. As part of the multivariate analysis, interactions among variables included in the logistic regression model were explored.

\section{Results}

Between January 2000 and June 2005, 220 patients with HLHS underwent a stage I palliation at Children's Hospital Boston. This time period was chosen because it represents our recent experience, but more importantly, it includes a sufficiently large cohort of patients to permit meaningful statistical comparisons. Postoperative echocardiographic data on the aortic arch were not available in 10 patients, and therefore they were excluded from the study. The remaining 210 patients constitute our final study population. There were $128(61 \%)$ male and $82(39 \%)$ female patients. Median age and weight at the time of stage I palliation were 5 days (range, 1-373 days) and $3.2 \mathrm{~kg}$ (range, 1.3-4.5 kg), respectively. The morphologic subgroups were aortic and mitral atresia in 47 (22\%) patients, aortic atresia and mitral stenosis in $39(19 \%)$ patients, aortic stenosis and mitral atresia in $8(4 \%)$ patients, aortic and mitral stenosis in $62(30 \%)$ patients, and HLHS anatomic variant in 54 (26\%) patients. The presence of a posterior shelf at the distal aortic arch was demonstrated by means of echocardiography in $90(43 \%)$ patients. One hundred fifty-three $(73 \%)$ patients had a modified Blalock-Taussig shunt at the time of stage I palliation, and 57 (27\%) patients had a right ventricle-to-pulmonary artery shunt. Aortic arch augmentation was performed with an aortic homograft in 115 (55\%) patients, a pulmonary homograft in $53(25 \%)$ patients, autologous pericardium in $30(14 \%)$ patients, and direct pulmonary-to-aorta connection in $12(6 \%)$ patients.

At a median follow-up of 1.7 years (range, 4 days-5.7 years) $172(82 \%)$ patients are alive, $170(81 \%)$ patients have had a stage II palliation, and $84(40 \%)$ patients have completed stage III of palliation. Twenty (10\%) of the 210 patients died in the hospital. Interstage mortality was $6 \%$ (13 patients). Weight at the time of the operation of less than $3 \mathrm{~kg}$ was significantly associated with early postoperative death $(P=.001)$; overall mortality for patients weighing 3 $\mathrm{kg}$ or greater was $4 \%(6 / 136)$, whereas it was $19 \%(14 / 73)$ in patients weighing less than $3 \mathrm{~kg}$ at the time of the stage 
I operation. There was also higher mortality in patients with aortic atresia-mitral stenosis $(P=.030)$. In the multivariate analysis weight at the time of the operation of less than $3 \mathrm{~kg}$ $(P=.002)$ and aortic atresia-mitral stenosis $(P=.023)$ were risk factors for death, with odds ratios of 5.0 and 3.3, respectively.

The incidence of a significant gradient, as determined by means of echocardiography, across the aortic arch after stage I palliation was $38 \%$ (80/210). Of these patients, 50 (24\%) had either balloon dilation, aortic arch augmentation, or both at follow-up. Factors significantly and inversely related to postoperative NAO on the basis of results of echocardiography or need for intervention were use of autologous material to enlarge the aortic arch and coarctectomy. In this latter group 20 patients received autologous pericardium for reconstruction of the aortic arch, 18 received a pulmonary homograft patch, 12 received an aortic homograft patch, and 5 underwent direct anastomosis between the aorta and the pulmonary trunk. Interestingly, shunt type or size was not related to development of NAO. Univariate and multivariate analysis are shown in Tables 1 and 2. In multivariate analysis statistically significant interactions between aortic coarctation and resection of the posterior shelf were detected; resection of the posterior shelf was associated with outcome in patients with aortic coarctation and not associated with outcome among those without aortic coarctation. The effect of coarctectomy is shown in Table 3.

\section{Discussion}

In this study we found that recurrent aortic arch obstruction occurred in $24 \%$ to $38 \%$ of infants after first-stage palliation for HLHS, depending on whether significant obstruction is defined by the need for arch intervention or by echocardiographic criteria, respectively. Thirty patients in our series with borderline diagnoses of NAO determined by means of echocardiography did not receive either balloon angioplasty or surgical arch reconstruction, depending on confirmation of the aortic arch gradient in the catheterization laboratory. Coarctectomy, use of autologous material for arch reconstruction, or primary connection of the pulmonary trunk to the aorta significantly reduced the incidence of recurrent arch obstruction after the Norwood procedure. Inversely, use of a homograft, especially an aortic wall homograft patch, for arch reconstruction was associated with a higher incidence of arch obstruction after first-stage palliation.

HLHS is marked by underdevelopment of the left-sided heart structures, including the aortic arch. The goal of the first stage of surgical palliation is to create a large and unobstructed pathway for systemic circulation. A wide variety of materials have been used to enlarge the aortic arch. ${ }^{13-17}$ Currently, the more common technique for arch augmentation in the Norwood operation includes the use of
TABLE 1. Echocardiographic NAO after stage I surgery

\begin{tabular}{|c|c|c|c|}
\hline Univariate analysis & All patients & NAO & $P$ value \\
\hline \multicolumn{4}{|l|}{ Preoperative data } \\
\hline Sex & & & NS \\
\hline Male & 128 & $52(41 \%)$ & \\
\hline Female & 82 & $28(34 \%)$ & \\
\hline $\begin{array}{l}\text { Age at surgical intervention } \\
\text { (range, 1-373 d) }\end{array}$ & & & NS \\
\hline$<7$ & 131 & $53(40 \%)$ & \\
\hline $7-13$ & 51 & $17(33 \%)$ & \\
\hline$\geq 14$ & 28 & $10(36 \%)$ & \\
\hline $\begin{array}{l}\text { Weight at surgical intervention } \\
\text { (range, } 1.3-4.5 \mathrm{~kg})\end{array}$ & & & .10 \\
\hline$<3$ & 73 & $22(30 \%)$ & \\
\hline$\geq 3$ & 136 & $57(42 \%)$ & \\
\hline Morphologic subgroup & & & NS \\
\hline Aortic atresia/mitral atresia & 47 & $18(38 \%)$ & \\
\hline Aortic atresia/mitral stenosis & 39 & $14(36 \%)$ & \\
\hline Aortic stenosis/mitral atresia & 8 & $1(13 \%)$ & \\
\hline Aortic stenosis/mitral stenosis & 62 & $28(45 \%)$ & \\
\hline HLHS variant & 54 & $19(35 \%)$ & \\
\hline Aortic Coarctation & & & .032 \\
\hline No/not known & 120 & $38(32 \%)$ & \\
\hline Yes & 90 & $42(47 \%)$ & \\
\hline \multicolumn{4}{|l|}{ Operative data } \\
\hline Shunt type & & & .15 \\
\hline RV-PA/Sano & 57 & $17(30 \%)$ & \\
\hline BT & 153 & $63(41 \%)$ & \\
\hline Shunt size & NS & & \\
\hline $3.0 \mathrm{~mm}$ & 5 & $1(20 \%)$ & \\
\hline $3.5 \mathrm{~mm}$ & 142 & $59(42 \%)$ & \\
\hline $4.0 \mathrm{~mm}$ & 14 & $7(50 \%)$ & \\
\hline $5.0 \mathrm{~mm}$ & 49 & $13(27 \%)$ & \\
\hline $\begin{array}{l}\text { Resection of posterior shelf of } \\
\text { coarctation }\end{array}$ & & & .015 \\
\hline No & 154 & $66(43 \%)$ & \\
\hline Yes & 55 & $13(24 \%)$ & \\
\hline Aortic arch augmentation & & & .065 \\
\hline Autologous pericardium & 30 & $6(20 \%)$ & \\
\hline Aortic homograft & 115 & $51(45 \%)$ & \\
\hline Pulmonary homograft & 53 & $18(34 \%)$ & \\
\hline Direct connection & 12 & $4(33 \%)$ & \\
\hline Multivariate analysis & Odds ratio & & $P$ value \\
\hline \multicolumn{4}{|l|}{ Patients with aortic coarctation } \\
\hline $\begin{array}{l}\text { Resection of posterior shelf } \\
\text { Patients without aortic } \\
\text { coarctation }\end{array}$ & 0.15 & & $<.001$ \\
\hline Resection of posterior shelf & 0.89 & & .82 \\
\hline
\end{tabular}

NAO, Neoaortic arch obstruction; HLHS, hypoplastic left heart syndrome; $R V-P A$, right ventricle-pulmonary artery; $B T$, Blalock-Taussig.

a heterologous tissue to augment the union of the native ascending aorta, transverse arch, and proximal pulmonary trunk. ${ }^{14,15}$ Pulmonary homografts are usually considered the best material to reconstruct the aortic arch because they can 
TABLE 2. Arch balloon angioplasty, arch reconstruction, or both after stage 1 surgery

\begin{tabular}{|c|c|c|c|}
\hline Univariate analysis & All patients & ABA/AR & $P$ value \\
\hline \multicolumn{4}{|l|}{ Preoperative data } \\
\hline Sex & & & NS \\
\hline Male & 128 & $30(23 \%)$ & \\
\hline Female & 82 & $20(24 \%)$ & \\
\hline $\begin{array}{c}\text { Age at surgical intervention } \\
\text { (range, } 1-373 \mathrm{~d})\end{array}$ & & & NS \\
\hline$<7$ & 131 & $35(27 \%)$ & \\
\hline $7-13$ & 51 & $12(24 \%)$ & \\
\hline$\geq 14$ & 28 & $3(11 \%)$ & \\
\hline $\begin{array}{c}\text { Weight at surgical intervention } \\
\text { (range, } 1.3-4.5 \mathrm{~kg})\end{array}$ & & & .17 \\
\hline$<3$ & 73 & $13(18 \%)$ & \\
\hline$\geq 3$ & 136 & $37(27 \%)$ & \\
\hline Morphologic subgroup & & & NS \\
\hline Aortic atresia/mitral atresia & 47 & $13(28 \%)$ & \\
\hline Aortic atresia/mitral stenosis & 39 & $9(23 \%)$ & \\
\hline Aortic stenosis/mitral atresia & 8 & $1(13 \%)$ & \\
\hline Aortic stenosis/mitral stenosis & 62 & $19(31 \%)$ & \\
\hline HLHS variant & 54 & $8(15 \%)$ & \\
\hline Aortic coarctation & & & .032 \\
\hline No/not known & 120 & $38(32 \%)$ & \\
\hline Yes & 90 & $42(47 \%)$ & \\
\hline \multicolumn{4}{|l|}{ Operative data } \\
\hline Shunt type & & & NS \\
\hline RV-PA/Sano & 57 & $15(26 \%)$ & \\
\hline BT & 153 & $35(23 \%)$ & \\
\hline Shunt size & & & NS \\
\hline $3.0 \mathrm{~mm}$ & 5 & $0(0 \%)$ & \\
\hline $3.5 \mathrm{~mm}$ & 142 & $33(23 \%)$ & \\
\hline $4.0 \mathrm{~mm}$ & 14 & $3(21 \%)$ & \\
\hline $5.0 \mathrm{~mm}$ & 49 & $14(29 \%)$ & \\
\hline $\begin{array}{l}\text { Resection of posterior shelf } \\
\text { of coarctation }\end{array}$ & & & .009 \\
\hline No & 154 & $44(29 \%)$ & \\
\hline Yes & 55 & $6(11 \%)$ & \\
\hline Aortic arch augmentation & & & .12 \\
\hline Autologous pericardium & 30 & $5(17 \%)$ & \\
\hline Aortic homograft & 115 & $32(28 \%)$ & \\
\hline Pulmonary homograft & 53 & $13(25 \%)$ & \\
\hline Direct connection & 12 & $0(0 \%)$ & \\
\hline Aortic arch augmentation & & & .045 \\
\hline Autologous tissue & 42 & $5(12 \%)$ & \\
\hline Homograft & 168 & $45(27 \%)$ & \\
\hline Multivariate analysis & & Odds ratio & $P$ value \\
\hline $\begin{array}{l}\text { Patients with aortic coarctation re } \\
\text { of posterior shelf } \\
\text { Patients without aortic coarctatio }\end{array}$ & section & 0.09 & .002 \\
\hline resection of posterior shelf & & 0.80 & .71 \\
\hline
\end{tabular}

$A B A$, Arch balloon angioplasty; $A R$, arch reconstruction; $H L H S$, hypoplastic left heart syndrome; $R V-P A$, right ventricle-pulmonary artery; $B T$, Blalock-Taussig.
TABLE 3. Resection of the posterior coarctation shelf: Effect modification

\begin{tabular}{lcc}
\hline Patients with: & Number & $\%$ NAO \\
\hline Echocardiographic gradient & & \\
Aortic coarctation + resection & 31 & 19 \\
Aortic coarctation + no resection & 59 & 61 \\
No aortic coarctation + resection & 24 & 29 \\
No aortic coarctation + no resection & 95 & 32 \\
B. Need for aortic balloon angioplasty and/or & & \\
$\quad$ arch reconstruction & & \\
Aortic coarctation + resection & 31 & 6 \\
Aortic coarctation + no resection & 59 & 42 \\
No aortic coarctation + resection & 24 & 17 \\
No aortic coarctation + no resection & 95 & $20 \%$
\end{tabular}

NAO, Neoaortic arch obstruction.

be trimmed with an aortic arch-like shape, and there is minimal surgical bleeding through suture holes. On the other hand, homografts are expensive, not easy to procure, and are prone to calcification and potentially stenosis. Autologous pericardium, however, is one of the most widely used materials for reconstruction in pediatric cardiac surgery. It is readily available, nonimmunoreactive, and reasonably hemostatic. When fixed with $0.6 \%$ glutaraldehyde, it is also easy to handle, and the risk of aneurysmal dilatation is reduced.

Recently, modification of the standard Norwood procedure without a homograft patch has been proposed as a superior alternative. ${ }^{7-10}$ Intuitively, it is attractive to assume that the elimination of patch material in aortic reconstruction might be associated with a lower incidence of late aortic arch obstruction because the immunoreactive material is not expected to grow and might lead to obstruction at the distal end of the patch. Interestingly, nearly all aortic arch obstruction after initial palliation of HLHS is detected in the first few months after repair. ${ }^{18,19}$ Moreover, previous studies on patients with aortic coarctation and a hypoplastic aortic arch have demonstrated that relief of obstruction at the site of coarctation allows transverse arch growth. ${ }^{18-20}$ These observations indicate that recurrent arch obstruction after the Norwood procedure is likely related to the technical adequacy of the reconstruction rather than to a lack of growth of the augmented aorta. In fact, Mahle and colleagues $^{21}$ found that in patients undergoing a Norwood procedure, growth of the reconstructed aorta parallels the rate seen in the healthy population. Postmortem investigations revealed that all the growth of the reconstructed aorta occurs in the native tissue that makes up at least a portion of the circumference of the aorta at every level. Furthermore, residual coarctation of the aorta can develop as a result of failure to extend the homograft around the arch.

A small-caliber neoaorta has been associated with increased mortality because of hemodynamic instability in the 
short-term and aortic coarctation in long-term follow-up. ${ }^{12}$ In our study, however, the presence of aortic atresia-mitral stenosis was associated with increased early mortality but not with recurrent arch obstruction. This finding implies that with current techniques, we have been able to mitigate hypoplastic aortic arch as a risk factor for NAO.

The existence of juxtaductal coarctation or a coarctation shelf is reported in more than $80 \%$ of the patients with HLHS, especially when the shelf of the ductal-like tissue located opposite the ductus arteriosum is included. ${ }^{4,5}$ This tissue has the potential to cause late obstruction. ${ }^{22}$ However, no standard surgical approach to this defect has been widely accepted. Moreover, contradictory data regarding this issue have been reported. Burkhart and colleagues ${ }^{23}$ have recently reported lower arch obstruction rates in patients undergoing the Norwood procedure with a technique that includes resection of the posterior shelf. However, Griselli and associates $^{24}$ have reported that the type of aortic arch reconstruction did not affect the incidence of need for arch intervention. In our study the presence of a preoperative posterior shelf was significantly associated with NAO and need for reintervention, reoperation, or both. Furthermore, coarctectomy significantly reduced the incidence of NAO. This association resulted in "effect modification"; that is, coarctectomy is particularly effective in patients with a preoperative diagnosis of coarctation. However, echocardiographic determination of coarctation at the level of the implantation of the ductus arteriosus is very challenging because of the presence of a large ductus and the subsequent turbulent blood flow at the ductal insertion into the descending thoracic aorta. Direct inspection might also play a role in deciding whether coarctectomy should be done. Moreover, other factors besides resection of coarctation could be involved in the development of NAO in HLHS. In fact, in our study the risk of NAO was higher in patients undergoing resection of coarctation when no preoperative diagnosis of a posterior shelf was made.

In summary, coarctectomy at the time of stage I palliation significantly reduces the incidence of NAO, especially in patients with a preoperative diagnosis of coarctation. Use of autologous tissue to reconstruct the arch is also associated with improved outcome. An aggressive approach to reconstruction of the aortic arch at the time of stage I palliation is advocated.

\section{References}

1. Fyler DC. Report of the New England Regional Infant Cardiac Program. Pediatrics. 1980;65:376-471.

2. Lev M. Pathologic anatomy and interrelationship of hypoplasia of the aortic tract complexes. Lab Invest. 1952;1:61-70.

3. Noonan JA, Nadas AS. The hypoplastic left hearth syndrome: an analysis of 101 cases. Pediatr Clin North Am. 1958;5:1029-56.

4. Von Reuden TJ, Knight L, Moller JH, Edwards JE. Coarctation of the aorta associated with aortic valvular atresia. Circulation. 1975;52: 951-4.
5. Hawkins JA, Doty DB. Aortic atresia. Morphologic characteristics affecting survival and operative palliation. J Thorac Cardiovasc Surg. 1984;88:620-6.

6. Norwood WI, Lang P, Hansen DD. Physiologic repair of aortic atresiahypoplastic left heart syndrome. N Engl J Med. 1983;45:87-91.

7. Fraser CD, Mee RBB. Modified Norwood procedure for hypoplastic left heart syndrome. Ann Thorac Surg. 1995;60(suppl):S546-9.

8. Bu'Lock FA, Stumper O, Jagtap R, Silove ED, De Giovanni JV, Wright JG, et al. Surgery for infants with hypoplastic systemic ventricle and severe outflow obstruction: early results with a modified Norwood procedure. Br Heart J. 1995;73:456-61.

9. Ishino K, Stumper O, De Giovanni JJV, Silove ED, Wright JG, Sethia B, et al. The modified Norwood procedure for hypoplastic left heart syndrome: early to intermediate results of 120 patients with particular reference to aortic arch repair. J Thorac Cardiovasc Surg. 1999;117: 920-30.

10. Poirier NC, Drummond-Webb JJ, Hisamochi K, Imamura M, Harrison AM, Mee RB. Modified Norwood procedure with a high-flow cardiopulmonary bypass strategy results in low mortality without late arch obstruction. J Thorac Cardiovasc Surg. 2000;120:875-84.

11. Bartram U, Grunenfelder J, Van Praagh R. Causes of death after the modified Norwood procedure: a study of 122 postmortem cases. Ann Thorac Surg. 1997;64:1795-802.

12. De Oliveira NC, Ashburn DA, Khalid F, Burkhart HM, Adatia IT, Holtby HM, et al. Prevention of early sudden circulatory collapse after the Norwood operation. Circulation. 2004;110(suppl 1):II133-8.

13. Gargiulo G, Napoleone CP, Solinas M, Frascaroli G, Pierangeli A. A new patch for the Norwood procedure. Ann Thorac Surg. 1999;68: 1873-4.

14. Pigott JD, Murphy JD, Barber G, Norwood WI. Palliative reconstructive surgery for hypoplastic left heart syndrome. Ann Thorac Surg. 1988;2:122-8.

15. Norwood WI. Hypoplastic left heart syndrome. Ann Thorac Surg. 1991;52:688-95.

16. Fraisse A, Colan SD, Jonas RA, Gauvreau K, Geva T. Accuracy of echocardiography for detection of aortic arch obstruction after stage I Norwood procedure. Am Heart J. 1998;135(suppl):230-6.

17. Jacobs ML. Aortic reconstruction in hypoplastic left heart syndrome: a reappraisal. J Thorac Cardiovasc Surg. 2000;120:872-4.

18. Siewers RD, Ettedgui J, Pahl E, Tallman T, Del Nido PJ. Coarctation and hypoplasia of the aortic arch: will the arch grow? Ann Thorac Surg. 1991;52:608-14.

19. Brouwer MH, Cromme-Dijkhuis AH, Ebels T, Eijgelaar A. Growth of the hypoplastic aortic arch after simple coarctation resection and end-to-end anastomosis. J Thorac Cardiovasc Surg. 1992;104:426-33.

20. Myers JL, McConnell BA, Waldhausen JA. Coarctation of the aorta in infants: does the aortic arch grow after repair? Ann Thorac Surg. 1992;54:869-75

21. Mahle WT, Rychick J, Weinberg PM, Cohen MS. Growth characteristics of the aortic arch after the Norwood operation. J Am Coll Cardiol. 1998;32:1951-4.

22. Jonas RA, Lang P, Hansen D, Hickey P, Castaneda A. First-stage palliation of hypoplastic left heart syndrome. The importance of coarctation and shunt size. J Thorac Cardiovasc Surg. 1986;92:6-13.

23. Burkhart HM, Ashburn DA, Konstantinov IE, De Oliveira NC, Benson L, Williams WG, et al. Interdigitating arch reconstruction eliminates recurrent coarctation after the Norwood procedure. $J$ Thorac Cardiovasc Surg. 2005;130:61-5.

24. Griselli M, McGuirk SP, Stumper O, Clarke AJ, Miller P, Dhillon R, et al. Influence of surgical strategies on outcome after the Norwood procedure. J Thorac Cardiovasc Surg. 2006;131:418-26.

\section{Discussion}

Dr James S. Tweddell (Milwaukee, Wis). Interstage survival, as well as improved candidacy for stage II palliation, depends on limiting the development of recurrent or residual lesions addressed in the initial stage I operation, including the prevention of coronary insufficiency, the development of a restricted atrial septal defect, 
the development of restriction of pulmonary blood flow, and, the subject of this presentation, prevention of aortic arch obstruction.

The authors have reviewed a 51/2-year experience with 210 patients with HLHS, with special attention to the issue of arch obstruction. The authors identified a posterior shelf in $47 \%$ of these 210 patients, and this was taken as evidence of coarctation.

One theory of coarctation suggests there is migration of ductal smooth muscle cells into the periductal aorta, with subsequent constriction and narrowing of the aortic lumen. Alternatively, in the case of infantile coarctation, we postulate that the hemodynamic lesion itself results in an imbalance between the larger ductus and the smaller adjacent aorta, such that a larger portion of the junction of these 2 structures is comprised of the ductal tissue, and the subsequent ductal involution results in coarctation.

Coarctation can therefore be thought of as one end of the spectrum of HLHS, and we could postulate an even greater imbalance in the proportion of ductus and the adjacent aorta, making coarctation a uniform part of this anomaly. Indeed, as pointed out in the discussion in your article, it is thought to occur in at least $80 \%$ of patients with HLHS. Prosthetic material that crosses this area of ductal tissue, which ultimately necroses and fibroses, will result in a circumferential ring of nonviable tissue that does not grow and is probably the substrate of recurrent coarctation.

The principal finding of this study was a decrease in the incidence of recoarctation in those patients whose posterior shelf was resected at the time of the stage I palliation. I agree completely with the authors' conclusions that excision of all ductal tissue reduces the risk of recurrent arch obstruction.

I am struck by a couple of findings in this study. First, a posterior shelf was found in only $90(47 \%)$ of the 210 patients. This shelf was resected in 55 patients, of whom only 6 required reintervention for arch obstruction. This left 35 patients with a posterior shelf who did not undergo resection, and yet 44 additional patients had recurrent arch obstruction. Therefore some patients who underwent a resection of the posterior shelf still required reintervention, and some patients who had no identifiable shelf still required reintervention.

At the Children's Hospital of Wisconsin, we use a coarctectomy with interdigitation, as described by both our own group and the group from Toronto Sick Kids Hospital. We have used this approach on 67 consecutive patients since July 2002. A little more than half had aortic atresia. Survival to stage II palliation was greater than $90 \%$. I say this only to point out that we did not lose a significant number of patients in the interstage period, and therefore we did not lose patients who might have experienced arch obstruction had they survived. We have had to reintervene in none of these patients for arch obstruction. Those data are very similar to the data that were reported by the group from Toronto as well. The technique therefore is very successful in eliminating that interstage problem.

Therefore I have the following questions for you. First, how do you know that the posterior shelf resection actually achieves the goal of complete excision of ductal tissue? Are there other mechanisms of arch obstruction that could be at play here?

Dr Bautista-Hernandez. In my opinion the key feature for neoaortic obstruction is resection of coarctation, but we also think that this resection plays a role in avoiding posterior or delayed coarctation, recoarctation. There might be other factors involved, but we did not look at those factors specifically in our studies.

Dr Tweddell. Would you care to speculate? I think you had some information on the type of additional tissue you used or the lack of additional tissue?

Dr Bautista-Hernandez. Additional tissue?

Dr Tweddell. Well, you talked about the use of homograft, either aortic or pulmonary; autologous pericardium; or no additional prosthetic material.

Dr Bautista-Hernandez. In our conclusions we show that autologous tissue, by means of direct connection between the pulmonary tract and the aorta or the use of autologous pericardium, was also associated with less recurrence of neoaortic obstruction, and therefore we think that autologous tissue is better-is a better tissue to use-than homografts, especially aortic homografts.

Dr Tweddell. In the patients without an obvious posterior shelf, how can you be certain that there is not some residual ductal tissue in that adjacent aortic tissue?

Dr Bautista-Hernandez. The thing is that diagnosis of a posterior shelf by means of echocardiography is sometimes difficult because of a large ductus and the subsequent turbulent flow. Therefore, we think that echocardiography is not enough to diagnose a posterior shelf. Therefore, the final decision should be done in the operating room by the surgeon, and sometimes you can see the posterior shelf, and echocardiography has not been used to diagnose the coarctation.

Dr Tweddell. Based on this excellent review and your presentation, are you going to consider a more radical resection of the potential ductal tissue-bearing areas in the future?

Dr Bautista-Hernandez. I think our resection is radical. What I mean is that this technique entails resection, transection of the aorta, resection of ductal tissue, counterincision into the descending thoracic aorta, and anastomosis between the aortic arch and the descending thoracic aorta. Therefore maybe we should look at that, but we think that it is radical enough.

Dr Glen Van Arsdell (Toronto, Ontario, Canada). I must say we face this issue as well and had similar obstruction until we did full coarctation resection.

I believed that we could not be certain that we were resecting the entire ductal tissue and therefore made counterincisions to cut any potential ductal ring. We actually made 2 counterincisions, one posteriorly and one anterolaterally. We call the resulting anastomosis an "interdigitating repair" (2 areas of interdigitating lamination). Like Dr Tweddell, we have not seen recurrent obstruction.

What I would like to talk about is transplantation. We see some late ventricular burnout, and those patients have one option: transplantation.

It turns out that they have become sensitized to the HLA antigens that are present in the homografts used for arch reconstruction. You operated on quite a number of patients with autologous pericardium and found that to be favorable. Most surgeons would think that it is harder to work with; however, from a sensitization perspective, it might be more favorable should later transplantation be required.

Can you describe to us your technique for use of autologous pericardium in arch reconstruction? 
Dr Bautista-Hernandez. The pericardium is harvested right after the sternotomy and is fixed with glutaraldehyde at $0.6 \%$ for 5 minutes. This procedure allows us to use the pericardium. It is easier to use, and it is easier to patch the aortic arch in this way. Therefore the description of the procedure is in the article.

Dr Van Arsdell. And bleeding and kinking issues, are there any extra issues in that regard?

Dr Pedro del Nido (Boston, Mass). If I could just comment because this is a technical question about the glutaraldehyde. I think this is an important question because, obviously, the concern is aneurysm.

It is autologous pericardium. It is fixed with $0.6 \%$ glutaraldehyde for 10 minutes. The key here is to use as little patch as possible. Therefore it is only to bridge the tiny gap in those few patients in whom direct connection of the pulmonary trunk to the aorta is not made. I think that is a critical point. We did not use large patches of pericardium; otherwise, you will see aneurysms.

Dr Charles D. Fraser (Houston, Tex). I have a couple of thoughts and questions related to this series, which sort of highlight what we believe; that is, as you have correctly pointed out, putting autologous tissue together is the best way to repair the arch in children.

I will say from the initial approach that I was taught by Dr Roger Mee-and that we certainly were very strong proponents of initially in Texas when I arrived there-we found that moving the distal arch and proximal descending aorta together really sort of eliminated the left aortopulmonary window, and we had a lot of trouble with the left pulmonary artery in that series of patients.

Therefore in the subsequent series of hypoblasts, we really modified the way we did it, much akin to the way Glen Van Arsdell and Jim Tweddell have described their techniques. Therefore I wonder what your thoughts are about that. In those patients in whom you were able to achieve a direct anastomosis, did you find more trouble with the left pulmonary artery?

Dr Bautista-Hernandez. Can you repeat, please?

Dr Fraser. Well, if you bring the aorta together, you bring the pulmonary artery up underneath the aortic arch without any intervening tissue, no patch, no pericardium. Do you find that that impinges on the left pulmonary artery more?

Dr Bautista-Hernandez. We used that technique only in $6 \%$ of the patients in our series. Therefore we did that overall in patients with favorable anatomy. What I mean is with a large pulmonary artery trunk and not a diminutive aorta. Therefore we did not see many problems with the pulmonary branches.

Dr Fraser. The other question that to me has broader implications is this: Has this experience in your Norwood population affected the way you handle arch hypoplasia and other lesions, such as transposition?

Dr Bautista-Hernandez. Yes. Dr del Nido, perhaps you would like to answer this.

Dr del Nido. This is a critical point, and I think Roger Mee's suggestion of using totally autologous tissue was very, very good, and we try to follow that concept whenever possible. What we find is that it is not applicable, at least in our hands, to all patients and that you do need a small gusset of patch material, and in that situation the pericardium works well.

Has it helped us with our other arch repairs? Absolutely. I think it has been very helpful for all arch reconstructions, including transposition patients with hypoplastic arch.

Dr Carlos J. Troconis (Caracas, Venezuela). Back in the late 1970 s and early 1980s, this issue of the posterior shelf arose from the subclavian flap repair for coarctation of aorta. But years after, the problem still continued, even removing the posterior shelf, as was recommended by many authors within the technique used. This issue was abolished after we started to perform extended end-to-end anastomosis for neonatal coarctation repair. Therefore in this track, I think and agree with Dr Tweddell that we should be more aggressive with entire resection of the periductal tissue and posterior shelf, trying to do end-to-end anastomosis whenever possible.

Dr Bautista-Hernandez. What we did was an end-to-end anastomosis between the aortic arch and the descending thoracic aorta. That is what we already did.

Dr Carl Backer (Chicago, Ill). I think that Richard Jonas wrote an editorial about "Should we resect ductal tissue?" in the discussion of coarctation, and the answer is yes. That seems to be true for HLHS also.

I have several brief questions. How were the patients selected for one technique or the other? Do you think there was any selection bias? Did certain surgeons prefer one technique over the other?

Dr Bautista-Hernandez. Yes, I think so. The decision of whether to use homograft or autologous tissue was done based on the surgeon's preference, and therefore there might be a bias. 